\title{
Callus of American ginseng (Panax quinquefolius) as a source of ginsenosides - medicinal secondary metabolites
}

\author{
EWA KOCHAN and ALEKSANDER CHMIEL \\ Department of Pharmaceutical Biotechnology, Medical University in Łódź, \\ Muszyńskiego 1, 90-151 Łódź, Poland \\ Corresponding author: Ewa Kochan, ewa.kochan@umed.lodz.pl
}

(Received on 24 February 2012; Accepted on 11 February 2013)

\begin{abstract}
Asian ginseng (Panax ginseng) and American ginseng (P. quinquefolius) are valuable medicinal herbs whose roots have been used for ages in traditional medicine in China and North America as vitalizing and stimulating agents. The roots are obtained mainly from field cultivation, which is a slow (5-7 years long), laborious, and troublesome process; so in vitro methods started to be used to produce ginseng biomass. In our study, non-organogenic callus of $P$. quinquefolius synthesized the same active substances like field roots, for more than 6 years. The ginsenosides are derivatives of protopanaxadiol $\left(\mathrm{Rb}_{1}, \mathrm{Rb}_{2}, \mathrm{Rc}, \mathrm{Rd}\right)$ or protopanaxatriol $\left(\mathrm{Rg}_{1}, \mathrm{Re}\right)$. The synthesis of $\mathrm{Rg}_{1}$ and $\mathrm{Re}$ metabolites is preferred in calli cultured in the dark and with ageing of culture.
\end{abstract}

Keywords: callus, ginsenosides, in vitro, ginseng, Panax quinquefolius

\section{INTRODUCTION}

The genus Panax L. includes perennial plants of family (Araliaceae). Roots of $P$. quinquefolius have been used for ages in traditional Indian medicine in North America. This species contains pharmacologically active ginsenosides (panaxosides) classified as triterpenoid saponins - derivatives of protopanaxadiol (e.g. $\mathrm{Rb}_{1}, \mathrm{Rb}_{2}, \mathrm{Rc}, \mathrm{Rd}$ ), known as the $\mathrm{Rb}$ group, and protopanaxatriol (e.g. $\mathrm{Rg}$, $\mathrm{Re}$ ), known as the $\mathrm{Rg}$ group (Fig. 1, Table 1) or derivatives of oleanolic acid (Ro).

Those metabolites generally strengthen the human organism (KIM et al. 2006) and are responsible for the herb's multidirectional adaptogenic action on the metabolic, hormonal, nervous, cardiovascular, and immunological systems (NOCERINO et al. 2000). Latest investigations show their immunomodulating (Lim et al. 2004; WANG et al. 2004; Shim et al. 2007), radioprotective (LeE et al. 2005; JAGETIA 2007; Kim et al. 2008), and anticancer activity (WANG et al. 2006, 2007, 2008; Li et al. 2008).

Nowadays, for commercial ginseng preparations, roots of $P$. quinquefolius and $P$. ginseng from field cultivation are obtained. Since obtaining of raw material is 


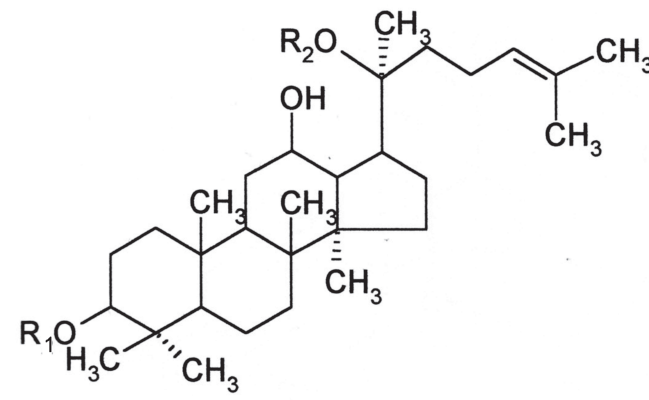

20(S)-protopanaxadiol $\quad\left(\mathrm{R}_{1}=\mathrm{R}_{2}=\mathrm{H}\right)$

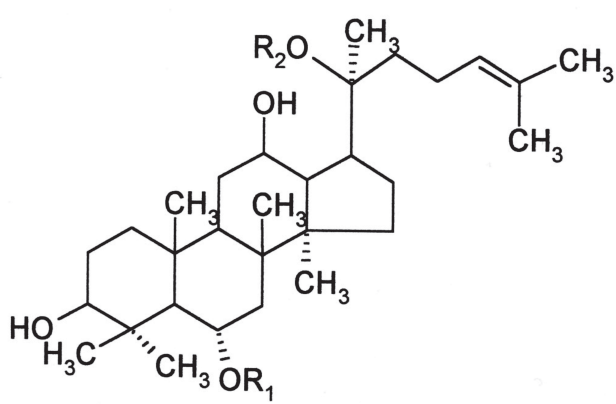

20(S)-protopanaxatriol $\left(\mathrm{R}_{1}=\mathrm{R}_{2}=\mathrm{H}\right)$

Fig. 1. Structure of protopanaxadiol and protopanaxatriol

Table 1. Sugar molecules in the structure of ginsenosides examined in this study. Glc = glucose; $\operatorname{ara}(\mathrm{p})=$ alpha-L-arabinopyranose; $\operatorname{ara}(\mathrm{f})=$ alpha-L-arabinofuranose; $r$ ha $=$ rhamnose

\begin{tabular}{lcc}
\hline \multicolumn{1}{c}{ Metabolite } & $\mathbf{R}_{\mathbf{1}}$ & $\mathbf{R}_{\mathbf{2}}$ \\
\hline $20(\mathrm{~S})$ - protopanaxadiol & $\mathrm{H}-$ & $\mathrm{H}-$ \\
$\mathrm{Rb}_{1}$ & Glc-Glc- & Glc-Glc- \\
$\mathrm{Rb}_{2}$ & Glc-Glc- & Glc- Ara(p) \\
$\mathrm{Rc}$ & Glc-Glc- & Glc- Ara(f) \\
$\mathrm{Rd}$ & Glc-Glc- & Glc- \\
$20(\mathrm{~S})$ - protopanaxatriol & H- & H- \\
$\mathrm{Re}$ & Glc- Rha & Glc- \\
$\operatorname{Rg}_{1}$ & Glc- & Glc- \\
\hline
\end{tabular}

time-consuming and laborious, an alternative biotechnological method of ginsenoside production by in vitro culture of $P$. ginseng has been developed (HiKINo 1991; HiBBINo \& UshiYAma 1998; Wu \& ZHONG 1999).

Commercial biotechnology for P. quinquefolius has not been developed yet. In our laboratory, callus, cell suspension, and different organ cultures were derived from seedlings of $P$. quinquefolius. This paper concerns the first stage of work, i.e. callus culture. The aim of our investigations was to determine if light and dark conditions and age of culture ( $0-6$ years) influence ginsenoside synthesis ability in non-organogenic callus culture of $P$. quinquefolius. Hitherto we have not found in the literature any information on biosynthesis of ginseng saponins in callus culture for such a long time. 


\section{MATERIAL AND METHODS}

\section{Callus culture}

The material for investigations comprised callus culture of $P$. quinquefolius of $\mathrm{Bl}_{3}$ line, which was initiated from a leaf blade of a 3-year-old plant originating from field cultivation at the Agricultural University of Lublin, Poland. The leaf blade was washed under running water with a detergent, and later disinfected using Domestos (containing 1-5\% sodium hypochlorite, according to Domestos sheet) and water (2:1, $\mathrm{v} / \mathrm{v}$ ) for $10 \mathrm{~min}$. Aseptic tissue fragments were rinsed 3 times in sterile distilled water and then placed on MS (Murashige \& SKOOG 1962) medium, which was supplemented with 2,4-D (2,4-dichlorophenoxyacetic acid) (1mg/1), NAA (1-naphthaleneacetic acid) (1 $\mathrm{mg} / 1)$, and BAP (6-benzylaminopurine) $(0.2 \mathrm{mg} / 1)$. Medium $\mathrm{pH}$ was 5.6-5.8, and all medium components were solidified using agar (0.7\% Difco Bacto Agar) and sterilized in an autoclave at $123^{\circ} \mathrm{C}$ (pressure latm.).

Callus cultures were placed in glass test tubes $(19 \mathrm{~cm} \times 2.5 \mathrm{~cm}$, containing $25 \mathrm{ml}$ of medium), at $26 \pm 2^{\circ} \mathrm{C}$ and continuous light $\left(40 \mu \mathrm{E} \mathrm{m}^{-2} \mathrm{~s}^{-1}\right)$ or in the dark. Every 5 weeks, callus was placed on a new portion of the medium.

\section{Culture growth measurement}

Fresh weight of the material, after separating tissue from the medium, was weighed and recorded. For dry weight assessment, tissue was dried at $100^{\circ} \mathrm{C}$ for $1 \mathrm{~h}$, and then at $80^{\circ} \mathrm{C}$ for $24 \mathrm{~h}$. Average initial weight of inoculum was $0.28 \mathrm{~g}$ fresh weight and $0.024 \mathrm{~g}$ dry weight $(\mathrm{dw})$. Data in Table 2 represent average values \pm standard errors of 3 replicates.

Table 2. Biomass of callus of $P$. quinquefolius line B1 3 growing on MS with 2,4-D (lmg/1), NAA $(\mathrm{mg} / 1)$, BAP $(0.5 \mathrm{mg} / 1)$, and sucrose $(50 \mathrm{~g} / 1)$. Inoculum was about $0.28 \mathrm{~g}$ of fresh biomass

\begin{tabular}{|c|c|c|c|c|}
\hline \multirow[t]{2}{*}{ Passages } & \multicolumn{2}{|c|}{ Fresh weight (g/callus) \pm SE } & \multicolumn{2}{|c|}{ Dry weight (g/callus) \pm SE } \\
\hline & dark & light & dark & light \\
\hline $11-14$ & $1.279 \pm 0.035^{\mathrm{a}}$ & $0.958 \pm 0.11^{\text {ac }}$ & $0.117 \pm 0.033^{\mathrm{a}}$ & $0.097 \pm 0.003^{\mathrm{ab}}$ \\
\hline $21-24$ & $2.774 \pm 0.052^{\mathrm{bc}}$ & $1.432 \pm 0.36^{\mathrm{bc}}$ & $0.199 \pm 0.064^{\mathrm{ab}}$ & $0.123 \pm 0.007^{\mathrm{b}}$ \\
\hline $31-34$ & $2.294 \pm 0.022^{b}$ & $1.476 \pm 0.22^{\mathrm{c}}$ & $0.182 \pm 0.066^{\mathrm{ab}}$ & $0.138 \pm 0.004^{\mathrm{ab}}$ \\
\hline $40-42$ & $3.333 \pm 0.76^{\mathrm{c}}$ & $0.672 \pm 0.09^{\mathrm{ab}}$ & $0.201 \pm 0.042^{b}$ & $0.055 \pm 0.001^{\mathrm{a}}$ \\
\hline $60-64$ & $3.554 \pm 0.036^{b c}$ & $0.698 \pm 0.088^{\mathrm{a}}$ & $0.247 \pm 0.037^{\mathrm{b}}$ & $0.056 \pm 0.009^{\mathrm{a}}$ \\
\hline
\end{tabular}

Data from individual passages were analysed using Friedman's ANOVA. Different letters within columns denote significant differences $(p<0.05)$.

\section{Extraction procedure}

Samples (about $1.0 \mathrm{~g}$ of dry raw material, $\pm 0.1 \mathrm{~g}$ ) were placed in $250-\mathrm{ml}$ flasks and extracted 3 times with $50 \mathrm{ml}$ of $80 \%$ methanol for 30 min under a reflux condenser 
at the solvent's boiling temperature. Combined methanol extracts were evaporated until dryness in a vacuum evaporator under the lowered pressure at $60^{\circ} \mathrm{C}$. The flask with dried residues was placed in a desiccator filled with a drying agent. The dried methanol extract was weighed. The treatment was repeated 3 times.

\section{High-performance liquid chromatography (HPLC)}

Dried extracts were dissolved in $2 \mathrm{ml}$ of methanol (HPLC grade) and filtered through Millex ${ }^{\circledR}$ - FG Hydrophobic Fluoropore filters (made of polytetrafluoroethylene, PTFE, with $0.2 \mu \mathrm{m}$ pore diameter). Then 5 - $\mu$ l aliquots were introduced to the liquid chromatography system consisting of LiChroART ${ }^{\circledR} 250-4$, Waters 600 Controller pump, and UV-VIS Waters 996 detector combined with Pentium 60 PC hardware equipped with Millenium software. As an eluent, mixtures of acetonitrile with water were used in the following ratios: (i) 30:70 for determination of $R b_{1}, R b_{2}, R c$, and $\mathrm{Rd}$ ginsenosides (flow rate $2 \mathrm{ml} / \mathrm{min}$, analysis time $45 \mathrm{~min}$ ), and (ii) 18:82 for determination of $\mathrm{Rg}_{1}$ and $\mathrm{Re}$ ginsenosides (flow rate $3 \mathrm{ml} / \mathrm{min}$, analysis time $40 \mathrm{~min}$ ). Ginsenoside detection was made at a wavelength of $203 \mathrm{~nm}$. Quantification of ginsenosides $(\mathrm{mg} / \mathrm{g} \mathrm{dw}$ ) was carried out by comparing retention times and peak areas between standards and samples. Data in Table 3 represent average values \pm standard errors of 3 replicates.

Table 3. Ginsenoside content $[\mathrm{mg} / \mathrm{g}$ dry weight \pm standard error $]$ in calli of $P$. quinquefolius

\begin{tabular}{|c|c|c|c|c|c|c|}
\hline & \multicolumn{3}{|c|}{ Dark } & \multicolumn{3}{|c|}{ Light } \\
\hline & $10-13$ & $30-33$ & $60-63$ & $10-13$ & $30-33$ & $60-63$ \\
\hline $\mathrm{Rb}_{1}$ & $0.89 \pm 0.1^{\mathrm{a}}$ & $1.01 \pm 0.4^{\mathrm{a}}$ & $1.12 \pm 0.2^{\mathrm{b}}$ & $0.77 \pm 0.21^{\mathrm{a}}$ & $0^{\mathrm{b}}$ & $0^{\mathrm{b}}$ \\
\hline $\mathrm{Rb}_{2}$ & $0.73 \pm 0.1^{\mathrm{a}}$ & $0^{\mathrm{b}}$ & $0^{\mathrm{b}}$ & $0^{\mathrm{a}}$ & $0^{\mathrm{a}}$ & $0^{\mathrm{a}}$ \\
\hline $\mathrm{Rc}$ & $0.17 \pm 0.12^{\mathrm{a}}$ & $0^{\mathrm{b}}$ & $0^{\mathrm{b}}$ & $0^{\mathrm{a}}$ & $0^{\mathrm{a}}$ & $0^{\mathrm{a}}$ \\
\hline $\mathrm{Rd}$ & $0.42 \pm 0.16^{\mathrm{a}}$ & $0^{\mathrm{b}}$ & $0^{\mathrm{b}}$ & $0^{\mathrm{a}}$ & $0^{\mathrm{a}}$ & $0^{\mathrm{a}}$ \\
\hline $\mathrm{Rb}$ Group & $2.21 \pm 0.11^{\mathrm{a}}$ & $1.01 \pm 0.48^{\mathrm{b}}$ & $1.12 \pm 0.22^{\mathrm{ab}}$ & $0.77 \pm 0.21^{\mathrm{a}}$ & $0^{\mathrm{b}}$ & $0^{\mathrm{b}}$ \\
\hline $\mathrm{Rg}_{1}$ & $1.31 \pm 0.15^{\mathrm{a}}$ & $1.24 \pm 0.22^{\mathrm{a}}$ & $1.19 \pm 0.12^{\mathrm{a}}$ & $0.80 \pm 0.02^{\mathrm{ab}}$ & $1.77 \pm 0.33^{\mathrm{b}}$ & $0.35 \pm 0.23^{\mathrm{a}}$ \\
\hline $\operatorname{Re}$ & $2.01 \pm 0.12^{\mathrm{a}}$ & $2.19 \pm 0.41^{\mathrm{a}}$ & $2.00 \pm 0.11^{\mathrm{a}}$ & $0.55 \pm 0.10^{\mathrm{a}}$ & $1.43 \pm 0.51^{\mathrm{a}}$ & $0.31 \pm 0.11^{b}$ \\
\hline Rg Group & $3.32 \pm 0.22^{\mathrm{a}}$ & $3.43 \pm 0.16^{\mathrm{a}}$ & $3.19 \pm 0.17^{\mathrm{a}}$ & $1.35 \pm 0.09^{\mathrm{ab}}$ & $3.20 \pm 0.11^{\mathrm{a}}$ & $0.66 \pm 0.08^{\mathrm{b}}$ \\
\hline Total & $5.53 \pm 0.31^{\mathrm{a}}$ & $4.44 \pm 0.67^{\mathrm{ab}}$ & $4.31 \pm 0.71^{\mathrm{b}}$ & $2.12 \pm 0.22^{\mathrm{a}}$ & $3.20 \pm 0.11^{\mathrm{a}}$ & $0.66 \pm 0.08^{b}$ \\
\hline
\end{tabular}

Data from individual passages were analysed using Friedman's ANOVA. Different letters within rows, for light and dark conditions separately, denote significant differences $(p<0.05)$.

\section{Standard solution}

Ginsenosides Rb1, Rb2, Rc, Rd, Re, and Rg1 were purchased from C.Roth $\mathrm{GmbH}+\mathrm{Co}$ Karlsruhe, Germany. A standard stock solution consisting of a mixture of ginsenosides Rb1, Rb2, Rc, Rd, Re, and Rg1 (10 mg/ml of each ginsenoside) was 
prepared in methanol of HPLC grade (J.T. Baker, Netherlands). A series of standard operating solutions of various concentrations were obtained by diluting the mixed standard stock solution.

\section{STATISTICAL ANALYSIS}

All treatments were in triplicates. Data were subjected to Kruskal-Wallis test $(p<0.05)$ or Friedman's ANOVA by ranks $(p<0.05)$, using STATISTICA version 10 software (STAT Soft).

\section{RESULTS}

\section{Morphology and growth of callus culture}

Callus began to appear in the second week of culture, first on the cutting surface of the explant, and later gradually embraced its whole surface. The callus was not differentiated macroscopically throughout the period of culture (60 passages every 5 weeks, i.e. 300 weeks in total). To the fifth passage, the cultures grew in the dark on MS medium with 2,4-D $(1 \mathrm{mg} / 1)$, NAA (1 mg/1), BAP (0.2 mg/1), and sucrose (30 g/1). The medium and the used concentrations of phytohormones were optimal for callus initiation and biomass growth in the initial passages. From the sixth passage, BAP concentration increased to $0.5 \mathrm{mg} / 1$ and sucrose concentration increased to $50 \mathrm{~g} / 1$ to maintain culture vitality. From the sixth passage, some cultures were placed in light. Callus cultures in the dark were yellow, friable, and lumpy. Growth index (i.e. percent increase in weight) ranged from 3.6 (passages 11-14) to 11.7 (passages 60-64). In the older cultures, fresh weight increased almost 3-fold, from about $1.3 \mathrm{~g}$ to about $3.6 \mathrm{~g}$, and dry weight above 2 -fold, from $0.12 \mathrm{~g}$ to $0.25 \mathrm{~g}$. Dry weight content of fresh callus biomass decreased over $25 \%$ during the study period, indicating that calli of the older generations contained greater amounts of water in their cells (Table 2).

Callus of line $\mathrm{B}_{3}$ cultured in light was yellow with deep red sectors, which increased in number and intensity during culture duration. Average fresh weight increased considerably, from $0.96 \mathrm{~g}$ (passages 11-14) to $1.48 \mathrm{~g}$ (passages 30-34), while dry weight from $0.097 \mathrm{~g}$ to $0.138 \mathrm{~g}$. In older cultures, after 60-64 passages, callus biomass was reduced to 0.698 $\mathrm{g}$ fresh weight and $0.056 \mathrm{~g}$ dry weight (Table 2).

The callus cultures growing in the dark achieved higher biomass increase in all examined passages, and both fresh and dry biomass did not change significantly between 21 and 64 passages. By contrast, the calli in light grew slowly and the highest biomass was noticed only between passages $21-24$ and passages $31-34$. The results referring to passages 40-42 show a considerable decrease in fresh and dry biomass, but later the biomass did not change significantly till the end of observations, i.e. passages 60-64.

\section{Saponin content}

Ginsenosides in the investigated calli of $P$. quinquefolius were analyzed qualitatively and quantitatively using HPLC. The ginsenoside content of calli of $\mathrm{Bl}_{3}$ line changed depending on culture time and conditions. Younger calli (passages 10-13), growing in the dark synthesized saponins of both groups (protopanaxadiol and protopanaxatriol deriv- 
atives). However, metabolites of the $\mathrm{Rg}$ group dominated and made up about $60 \%$ of total examined saponins. Concentrations of $\mathrm{Re}$ and $\mathrm{Rg}_{1}$ saponins reached $2 \mathrm{mg} / \mathrm{g} \mathrm{dw}$ and 1.3 $\mathrm{mg} / \mathrm{g}$ dw, respectively. Ginsenosides $\mathrm{Rb}_{1}$ and $\mathrm{Rb}_{2}$ were found in lower amounts $(0.9 \mathrm{mg} / \mathrm{g}$ $\mathrm{dw}$ and $0.7 \mathrm{mg} / \mathrm{g} \mathrm{dw}$, respectively) and accounted for half of the total level of the Rg group. $\mathrm{Rd}$ content exceeded $0.4 \mathrm{mg} / \mathrm{g} \mathrm{dw}$, and the level of Rc was the lowest (Table 3 ).

In older calli (passages 30-33 and 60-63), the level of ginsenosides of the $\mathrm{Rg}$ group changed insignificantly. Out of this group, only $\mathrm{Rb}_{1}$ was detected. Its level in passages 30-33 was similar to $\mathrm{Rb}_{1}$ content of the extracts isolated from the youngest calli and slightly increased in passages 60-64 (Table 3).

Calli cultured in light synthesized less ginsenosides than calli growing in the dark (significant differences, Kruskal-Wallis test, $\mathrm{p}<0.05$ ). The level of individual panaxosides of the $\mathrm{Rg}$ group was variable during culture time. The highest amounts of $\mathrm{Rg}_{1}$ and $\mathrm{Re}$ were found in calli after 30-33 passages and the levels of $\operatorname{Rg}_{1}$ and Re increased above 2-fold compared to younger calli. After 60 passages, we noted a significant decrease in concentrations of $\mathrm{Rg}_{1}$ and $\mathrm{Re}$. Among ginsenosides of the $\mathrm{Rb}$ group, only $\mathrm{Rb}_{1}$ metabolite was detected in the youngest calli; in older passages it was not found at all (Table 3).

\section{DISCUSSION}

Biosynthesis of secondary metabolites is often related to plant tissue differentiation (Morimoto et al. 1994; KnÖss 1995; Ellis et al. 1996; Karam et al. 2003). This does not seem to be a general rule for plant tissue culture. We have found in our study that non-differentiated callus of $P$. quinquefolius is capable of biosynthesis of ginsenosides and their accumulation. Young calli cultured in the dark synthesized all the examined metabolites but calli cultured in light produced both $\operatorname{Rg}_{1}$ and $\mathrm{Re}$ saponins of the $\mathrm{Rg}$ group and $\mathrm{Rb}_{1}$ metabolite of the $\mathrm{Rb}$ group. In older calli growing in light, only saponins of the $\mathrm{Rg}$ group were found. The results obtained for younger calli indicate that the enzymes responsible for synthesis of protopanaxadiol derivatives in calli growing in light are less active than in calli cultured in the dark. Protopanaxatriol derivatives, i.e. metabolites of the Rg group, were synthesized in older calli irrespective of culture conditions. These observations suggest that the activity of enzymes taking part in biosynthesis of protopanaxatriol derivatives is dominating in non-organogenic callus of $P$. quinquefolius.

Mathur et al. (2000) showed that after 5 weeks of growth of undifferentiated tissue of $P$. quinquefolius in variable light conditions (light/dark $16 \mathrm{~h} / 8 \mathrm{~h}$ cycle), it also synthesized mostly protopanaxatriol derivatives $\operatorname{Rg}_{1}$ and $\mathrm{Re}$, and like in our work, $\operatorname{Rg}_{1}$ was dominant. Rc and Rd saponins were found at low levels.

Moreover, MATHUR et al. (1999) investigated saponin biosynthesis in callus culture of $P$. quinquefolius, $P$. sikkimensi and P. pseudoginseng in passages 4, 8, and 13 . For callus cultures of $P$. quinquefolius it was found that the oldest cultures synthesized all the examined protopanaxadiol derivatives $\left(\mathrm{Rb}_{1}, \mathrm{Rb}_{2}, \mathrm{Rc}, \mathrm{Rd}\right)$, and $\mathrm{Rb}$ was dominant. The calli also synthesized all the examined protopanaxatriol derivatives $\left(\mathrm{Rg}_{1}, \mathrm{Re}, \mathrm{Rf}\right)$, with the highest content of $\mathrm{Rg}_{1}$. In that work, however, the authors did not define light conditions. WANG et al. (1999) noted that 5.5-month-old callus of P.quinquefolius synthesized less than $2 \mathrm{mg} / \mathrm{g}$ dw of total saponins. $\mathrm{Rb}_{1}$ and $\mathrm{Re}$ ginsenosides dominated quantitatively, and 
the level of each of them did not exceed $1 \mathrm{mg} / \mathrm{g} \mathrm{dw}$. Those authors (WANG et al. 1999) also reported that plantlets deriving from somatic embryos produced $6.6 \mathrm{mg} / \mathrm{g} \mathrm{dw}$ of total saponins, and ginsenosides Re and Rd prevailed among all investigated saponins.

CHOI et al. (1994) shows opposite results of light influence on ginsenoside production in calli of Asian ginseng ( $P$. ginseng). In that case, light stimulated total saponin production. Different species of ginseng and different culture conditions (e.g. type of explant used to initiate callus culture, phytohormone concentrations) may be probable factors determining the different observations described by CHOI et al. (1994) and in this paper. Also it is worth noting that cell or callus cultures of $P$. quinquefolius growing in light and studied in this paper accumulated red pigment, so it is expected that metabolic pathways can be shifted towards the synthesis of the pigment and not the ginseng saponins.

HuAng et al. (2010) noticed that callus culture of $P$. ginseng growing in the dark synthesized ginsenosides $R e, R_{1}$, and $R b_{1}$. The sum of the 3 saponins $(0.9 \mathrm{mg} / \mathrm{g})$ and also the levels of individual ginsenosides were lower than in our study. Native taproots, hairy roots cultured in solid medium, and hairy roots cultured in liquid medium, synthesized 2.72, 0.55, and $1.62 \mathrm{mg} / \mathrm{g}$ of the 3 ginsenosides, respectively (HuANG et al. 2010). In contrast to results shown in this paper and by HuANG et al. (2010), LANGHANsova et al. (2005) reported that callus culture of $P$. ginseng did not synthesize ginsenoside Re at all. Total content of other saponins $(12.78 \mathrm{mg} / \mathrm{g})$ was higher than in investigations described by HuANG et al. (2010) and in this paper. LANGHANSOVA et al. (2005) also showed that native roots, adventitious root cultures from Erlenmeyer flasks and bioreactor, and suspension cultures growing in flasks and bioreactor produced more saponins than callus cultures.

In general it seems, according to our study, that synthesis of the Rg group metabolites is preferred especially in calli growing in the dark, regardless of callus age, while protopanaxadiol derivatives are synthesized only in the youngest calli in the nonorganogenic callus culture of $P$. quinquefolius. Calli growing in light produced less saponins than those cultured in the dark but instead they synthesized a red pigment.

\section{REFERENCES}

Chor K. T., Ahn I. O., Park J. S. 1994. Production of ginseng saponin in tissue culture of ginseng (Panax ginseng C.A. Meyer). Russian J. Plant Physiol. 41:784-788.

Ellis D. D., Zeldin E., Brodhagen M., Russin W. A., Mccown B. H. 1996. Taxol production in nodule cultures of Taxus. J. Nat. Prod. 59: 246-250.

HibBino K., UshiYAma K. 1998. Commercial production of ginseng by plant cell culture technology. In: Plant Cell Culture for the production of Food Ingredients Proceedings of ACS symposium, (Fu Tu., Singh G., Curtis Wr., Eds.) April 13-17, San Francisco, CA, Plenum, New York.

Hikino H. 1991. Traditional remedies and modern assessment the case of ginseng. In: The medicinal plant industry. (WIJESEKeRA R. O. B., Ed.), Chapter 11, p.149-162, CRC Press. Boca, Raton.

Huang T., Gao W. Y., Wang J., Cao Y., Zhao Y. X., Liu C. X. 2010. Selection and optimization of a high-producing tissue culture of Panax ginseng C. A. Meyer. Acta Physiol. Plant. 32: 765-772.

Jagetia C. G. 2007. Radioprotective Potential of Plants and Herbs against the Effects of Ionizing Radiation. J. Clin. Biochem. Nutr. 40: 74-81. 
Karam S. N., Jawad F. M., Arikat N. A., Shibli R. A. 2003. Growth and rosmarinic acid accumulation in callus, cell suspension, and root cultures of wild Salvia fruticosa. Plant Cell Tissue and Organ. Cult. 73: 117-121.

Kim H. J., Kim M. H., Byon Y. Y., Park J. W., Jee Y., Joo H. G. 2008. Radioprotective effects of an acidic polysaccharide of Panax ginseng on bone marrow cells. J. Vet. Sci. 9: 359-365.

Kim J. H., Park C. Y., Lee S. J. 2006. Effects of sun ginseng on subjective quality of life in cancer patients: a double-blind, placebo-controlled pilot trial. J. Clin. Pharm. Ther. 31: 331-334.

KNöss W. 1995. Establishment of callus, cell suspension and shoot cultures of Leonurus cardiaca L. and diterpene analysis. Plant Cell Rep. 14: 790-793.

Langhansova L., Marsik P., VaneK T. 2005. Production of saponins from Panax ginseng suspension and adventitious root cultures. Biol. Plant. 49: 463-465.

Lee T. K., Johnke R. M., Allison R. R., O'brien K. F., Dobbs L. J. 2005. Radioprotective potential of ginseng. Mutagenesis 20: 237-243.

Li Q. F., Shi S. L., Liu Q. R., Tang J., Song J., Liang Y. 2008. Anticancer effects of ginsenoside Rg1, cinnamic acid, and tanshinone IIA in osteosarcoma MG-63 cells: nuclear matrix downregulation and cytoplasmic trafficking of nucleophosmin. Int. J. Biochem. Cell Biol. 40: 1918-1929.

Lim T. S., Na K., Chor E. M., Chung J. Y., Hwang J. K. 2004. Immunomodulating activities of polysaccharides isolated from Panax ginseng. J. Med. Food. 7: 1-6.

Mathur A., Mathur A. K., Gangwar A. 2000. Saponin production by cell/callus cultures of Panax species. In: Saponins in Food, Feedstuff and Medicinal Plants (Oleszer W., Martson A., Ed.), Kluwer Academic Publishers, Dordrecht/Boston/London

Mathur A., Mathur A. K., Pal M., UniYal G. C. 1999. Comparison of qualitative and quantitative in vitro ginsenoside production in callus cultures of three Panax species. Planta Med. 65: 484-486.

Morimoto S., Goto Y., Shoyama Y. 1994. Production of lithospermic acid B and rosmarinic acid in callus tissue and regenerated plantlets of Salvia miltiorrhiza. J. Nat. Prod. 57: 817-823.

Murashige T., Skoog F. 1962. A revised medium for rapid growth and bioassays with tobacco tissue cultures. Physiol. Plant. 15: 473-497.

Nocerino E., Амato M., Izzo A. A. 2000. The aphrodisiac and adaptogenic properties of ginseng Fitoterapia 71, Supplement 1, 1 Aug, S1-S5.

Shim J. Y., HAN Y., Ahn J. Y., Yun Y. S., Song J. Y. 2007. Chemoprotective and adjuvant effects of immunomodulator ginsan in cyclophosphamide-treated normal and tumor bearing mice. Int. J. Immunopathol. Pharmacol. 20: 487-97.

Wang C. Z., Aung H. H., Ni M., Wu J. A., Tong R., Wicks S., He T. C., Yuan C. S. 2007. Red American ginseng: ginsenoside constituents and antiproliferative activities of heat-processed Panax quinquefolius roots. Planta Med. 73: 669-674.

Wang C. Z., Zhang B., Song. W. X., Wang A., Ni M., Luo X., Aung H. H., Xie J. T., Tong R., He T. C., YUAN C. S. 2006. Steamed American ginseng berry: ginsenoside analyses and anticancer activities. J. Agric. Food Chem. 54: 9936-9942.

Wang M., Larry J., Li G. J., Wu Y., Pang P., Tapan K., Basu Shan J. J. 2004. A proprietary extract from North American ginseng (Panax quinquefolium) enhances IL-2 and IFN-productions in murine spleen cells induced by Con-A. Int. Immunopharm. 4: 311-315.

Wang W., Rayburn E. R., Hao M., Zhao Y., Hill D. L., Zhang R., Wang H. 2008. Experimental therapy of prostate cancer with novel natural product anti-cancer ginsenosides. Prostate 1, 68: 809-819.

Wang X., Proctor J. T. A., Kakuda Y., Raj S. K., Saxena P. R. 1999. Ginsenosides in American ginseng: comparison of in vitro derived and field-grown plant tissues. J. Herbs, Spices \& Medicinal Plans 6: 1-10.

Wu J., ZHONG J. J. 1999. Production of ginseng and its bioactive components in plant culture: current technological and applied aspects. J. Biotechnol. 68: 89-99. 